\title{
Study on Adsorption of Dye Wastewater by Modified Fly Ash
}

\author{
Yanping $\mathrm{Qu}^{1, \mathrm{a}^{*}}$, Dongqing Yan ${ }^{1, \mathrm{~b}}$, Rushuang $\mathrm{Su}^{1, \mathrm{c}}$, Wenshuo $\mathrm{Hu}^{1, \mathrm{~d}}$, Yanyan Dai ${ }^{1, \mathrm{e}}$ \\ ${ }^{1}$ School of Chemistry and Biological Engineering, Qilu Institute of Technology, Jinan, Shandong, China
}

\begin{abstract}
Used fly ash as raw material, it was modified by acid, alkali and high temperature to produce modified fly ash adsorbent, sulfuric acid modified fly ash adsorbent, sodium hydroxide modified fly ash adsorbent and high temperature modified fly ash adsorbent. In this paper, the effects of adsorbent dosage, adsorbent adsorption time, initial dye concentration, wastewater $\mathrm{pH}$ and temperature on dye adsorption were studied. The results showed that: the acid modified fly ash adsorbent had a good treatment effect on the dye; when the dosage of fly ash was $1.00 \mathrm{~g}$, the adsorption time was $90 \mathrm{~min}$, the $\mathrm{pH}$ of wastewater was 4 , and the temperature was $45{ }^{\circ} \mathrm{C}$, the decolorization rate of $60 \mathrm{mg} / \mathrm{L}$ methyl orange dye can reached more than $70 \%$; when the dosage of fly ash was $0.20 \mathrm{~g}$, the adsorption time was $60 \mathrm{~min}$, the $\mathrm{pH}$ of wastewater was 3 , and the temperature was $35{ }^{\circ} \mathrm{C}$, the decolorization rate of $20 \mathrm{mg} / \mathrm{L}$ methyl orange dye can be achieved. The decolorization rate of Congo red can reached more than $80 \%$.
\end{abstract}

\section{Introduction}

Although dyes have brought people a colorful world and high economic benefits, they have also produced "three wastes" which are difficult to treat, especially a large amount of wastewater needs to be discharged. According to the survey, the average water consumption per ton of dye wastewater was 300-350 $\mathrm{t}^{[1]}$. In recent years, many scholars at home and abroad have carried out in-depth research on it. The main treatment methods include extraction, membrane separation, oxidation catalysis and adsorption $^{[2,3]}$. The adsorption method uses adsorbent to selectively enrich dyes in wastewater, which avoids the use of organic solvents and is safe to operate. Fly ash is one of the main solid wastes in the world. It not only occupies a large area, but also the suspended particles harm human health. In this paper, modified fly ash was used as adsorbent to treat methyl orange and Congo red dye wastewater, and the influence of different factors on the adsorption effect was studied.

\section{Experimental methods}

\subsection{Preparation of sulfuric acid modified fly ash}

Dilute 6 times sulfuric acid into $3 \mathrm{~mol} / \mathrm{L}$ sulfuric acid, accurately measured $100.00 \mathrm{~mL}$ deionized water into 250 $\mathrm{mL}$ beaker, slowly added $20.00 \mathrm{~mL}$ sulfuric acid (18 $\mathrm{mol} / \mathrm{L}$ ), added $24.00 \mathrm{~g}$ fly ash (FA, liquid-solid ratio 6:1) into it, heated at $90{ }^{\circ} \mathrm{C}$ and stirred for $3 \mathrm{~h}$. After the soaking solution was poured out, it was washed to neutral with deionized water, dried and cooled for standby, and then the fly ash adsorbent (AFA) with properties changed by sulfuric acid was obtained.

\subsection{Preparation of sodium hydroxide modified fly ash}

Accurately weighed $12.00 \mathrm{~g}$ sodium hydroxide and dissolved it into $100.00 \mathrm{ml}$ water to prepare $3 \mathrm{~mol} / \mathrm{L}$ sodium hydroxide solution. Weighed $20.00 \mathrm{~g}$ of fly ash and the sodium hydroxide solution into a $250 \mathrm{ml}$ beaker (liquid-solid ratio 5:1), heated it at $90{ }^{\circ} \mathrm{C}$ and stirred it for $3 \mathrm{~h}$, then dried it for cold standby to obtain alkali modified fly ash adsorbent (SFA).

\subsection{Preparation of high temperature modified fly ash}

Accurately weighed $20.00 \mathrm{~g}$ of fly ash, put it into the oven, heated it at $100{ }^{\circ} \mathrm{C}$ for $2 \mathrm{~h}$, and then took it out. When the temperature dropped to room temperature, we can got high temperature modified fly ash adsorbent (TFA).

\subsection{Comparison of adsorption performance of different modification methods}

Took $8250 \mathrm{~mL}$ conical flasks and added $100.00 \mathrm{~mL}$ of methyl orange and Congo red dye with the concentration of $40 \mathrm{mg} / \mathrm{L}$ respectively. Accurately added $0.20 \mathrm{~g}$ of AFA, SFA, TFA and FA, and put the conical flask on the magnetic stirrer. After stirred for $1 \mathrm{~h}$ at a constant speed, filter and measured the absorbance.

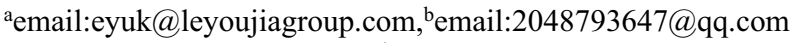

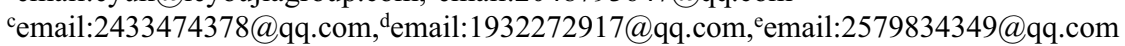

*Corresponding author's e-mail: eyuk@leyoujiagroup.com 


\section{Results and analysis}

\subsection{Comparison of different modification methods}

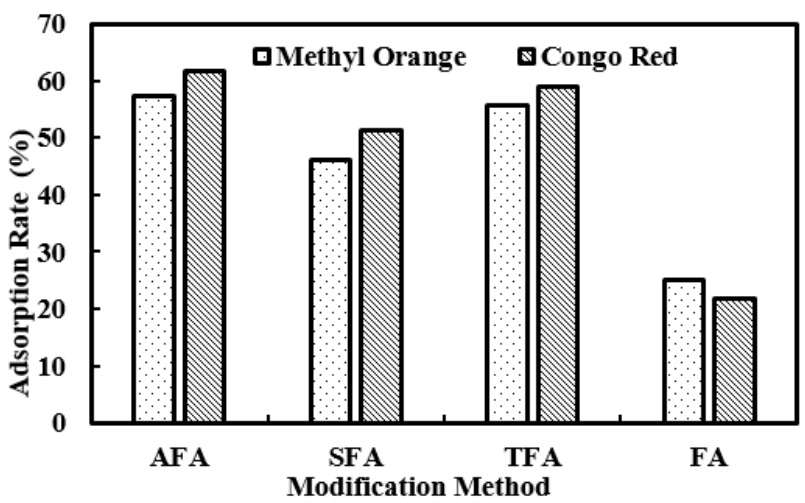

Figure 1.Comparison of modification methods

As shown in Figure 1, the adsorption rate of SFA has increased compared with FA. The adsorption rate of SFA is the lowest among the three modified adsorbents, which is over $45 \%$. There is a large amount of silica on the surface of fly ash, and it is modified with sodium

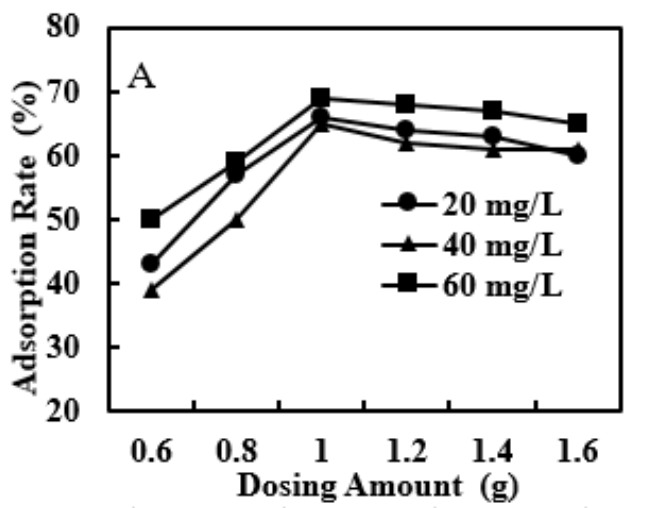

hydroxide. The silica on the surface will generate a variable charge due to chemical dissociation, which will damage the surface of fly ash. Making those soluble substances react with sodium hydroxide to form gel substances will improve the adsorption capacity very well ${ }^{[4]}$.Compared with FA, the adsorption rate of TFA is much higher than that of FA, which can reach more than $58 \%$. Because the moisture inside the fly ash particles will be evaporated to dryness at higher temperatures, resulting in an increase in the specific surface area and a significant increase in the pores that can be adsorbed in the particles, the adsorption performance will be greatly improved. AFA has the best adsorption effect, and the adsorption rate can reach more than $61 \%$. Compared with FA, the adsorption rate of AFA is much higher than that of FA. Because the fly ash modified by sulfuric acid solution will form many tiny pores and grooves on the particle surface, and the fly ash modified by sulfuric acid will release a large amount of cations, which can make the potential in the water drop rapidly and the suspended particles lose stability. It is quickly adsorbed on the particle surface ${ }^{[5]}$. Therefore, the paper chooses AFA as the adsorbent.

\subsection{Determination of AFA dosing amount}

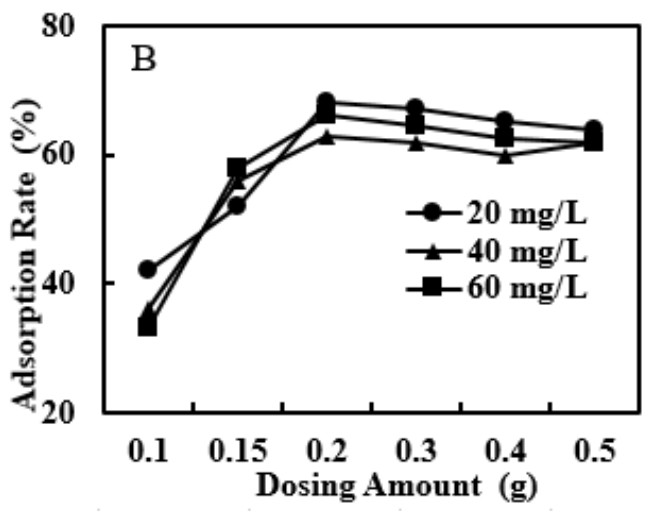

Figure2. The effect of AFA dosage on the adsorption performance of methyl orange (A) and Congo red (B)

It can be seen from Figure 2 that the adsorption rate of methyl orange can reach $69 \%$ when the dosage of AFA is $1.00 \mathrm{~g}$, and the adsorption rate of Congo red can reach up to $66 \%$ when the dosage of AFA is $0.20 \mathrm{~g}$, and then the trend gradually stabilizes. The reason is that AFA generates a large amount of amorphous active materials, and the increase of active ingredients increases the adsorption performance of fly ash ${ }^{[6]}$. When the dosage exceeds $1.00 \mathrm{~g}$ and $0.20 \mathrm{~g}$, it indicates that the adsorption has reached stable at the moment. Therefore, the paper chooses AFA of $1.00 \mathrm{~g}$ as the dosage for the adsorption of methyl orange, and $0.20 \mathrm{~g}$ as the dosage for the adsorption of Congo red.

\subsection{Determination of AFA adsorption time}

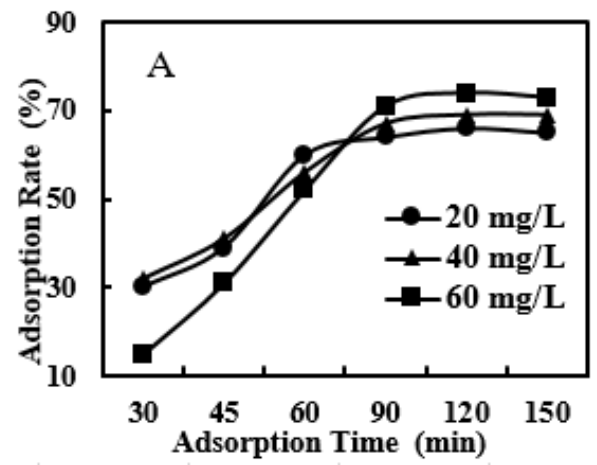

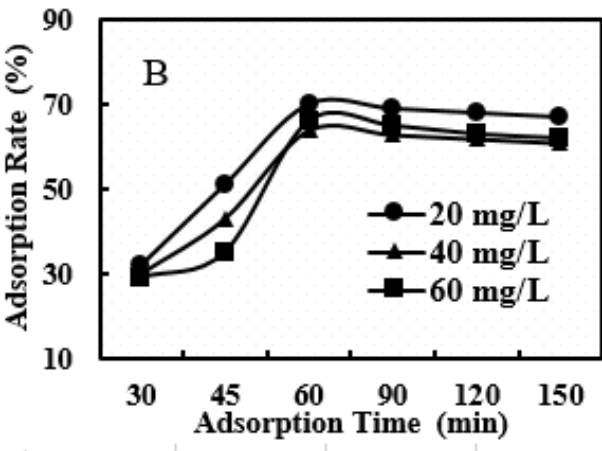

Figure 3. The effect of adsorption time on the adsorption performance of methyl orange (A) and Congo red (B) 
It can be seen from Figure 3 that when the concentrations of methyl orange and Congo red are $20 \mathrm{mg} / \mathrm{L}, 40 \mathrm{mg} / \mathrm{L}$, and $60 \mathrm{mg} / \mathrm{L}$, the adsorption time increases after the optimal dosage is added, and the adsorption rate will also increase, while the AFA The adsorption time for methyl orange gradually stabilized after $90 \mathrm{~min}$, and the adsorption rate reached $72 \%$ at this time. After the adsorption time of AFA on Congo red reaches 60 minutes, the growth trend slows down and even has a slight downward trend, at which time the adsorption rate is $71 \%$. Because in the initial stage of adsorption, surface adsorption plays a major role, the concentration of dye in the solution is relatively high, AFA can provide more adsorption active points, resulting in a very significant increase in adsorption efficiency. After the adsorption process for a period of time, the dye concentration in the solution is getting lower and lower, and the active sites of AFA are largely occupied close to the saturated state, and no more active sites can be provided. The dye molecules gradually diffuse from the surface to the internal pores, resulting in The adsorption becomes slower and slower, the adsorption rate decreases, the removal rate no longer rises, and finally the adsorption reaches equilibrium ${ }^{[7]}$. When the methyl orange simulated dye is adsorbed for 90 min, the adsorption rate tends to be stable. At this time, the adsorption rate of AFA for the concentration of $60 \mathrm{mg} / \mathrm{L}$ is the highest. When the adsorption time of Congo red reaches $60 \mathrm{~min}$, the adsorption rate tends to be stable. At this time, the adsorption rate of AFA to the dye with a concentration of $20 \mathrm{mg} / \mathrm{L}$ is the highest. Therefore, the paper chooses $90 \mathrm{~min}$ as the AFA adsorption time to simulate the dye for methyl orange; chooses $60 \mathrm{~min}$ as the AFA adsorption time as the best adsorption time for Congo red.

\subsection{Influence of initial concentration on treatment effect}

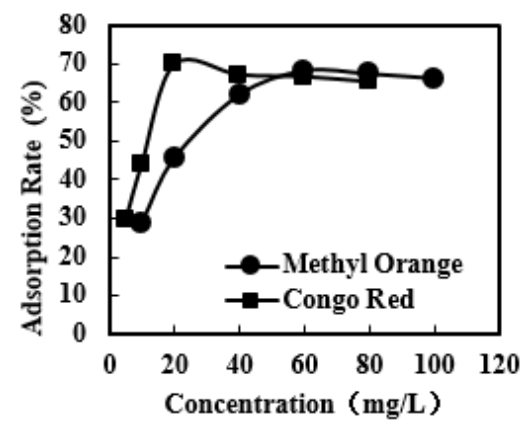

Figure 4. The effect of initial concentration on the adsorption performance of methyl orange and Congo red

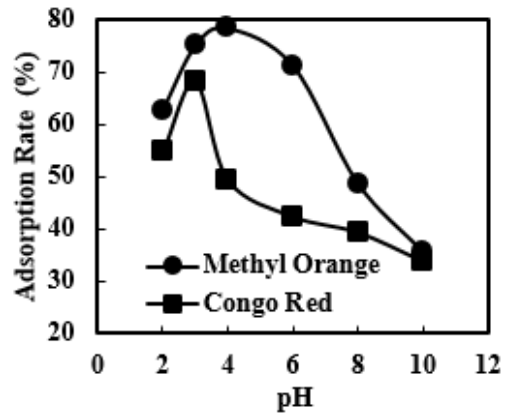

Figure 5. The effect of $\mathrm{pH}$ on the adsorption performance of methyl orange and Congo red

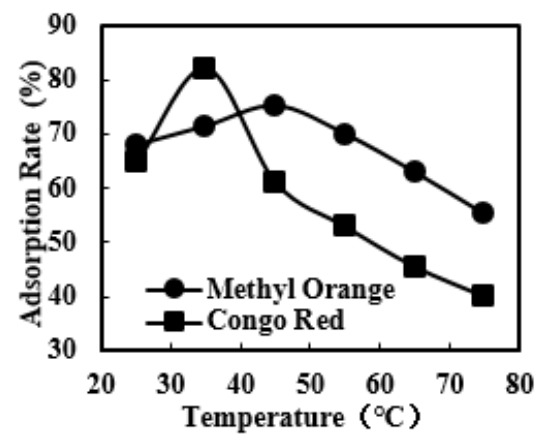

Figure 6.The effect of temperature on the adsorption performance of methyl orange and Congo red
It can be seen from Figure 4 that when the concentration increases, the adsorption rate also increases, but when the concentration reaches a certain level, the adsorption rate stops increasing and tends to stabilize. At this time, the adsorption rate is $68 \%$. When the concentration of Congo red reaches $20 \mathrm{mg} / \mathrm{L}$, the adsorption rate growth trend slows down, and the adsorption rate is $69 \%$ at this time. When the dye concentration is low, the groups on the surface of AFA that can provide adsorption active sites are in an unsaturated state, and there are more surface active adsorption sites that can quickly adsorb to the dye, which will show high removal efficiency. When the dye concentration becomes higher, most of the active adsorption sites are saturated, and there are fewer surface active adsorption sites that can be adsorbed with the dye, so the unsaturated state gradually tends to the saturated state, and the AFA in the solution is close to the adsorption equilibrium ${ }^{[8]}$, The dye concentration is excessive and is no longer adsorbed, and finally leads to a decrease in the adsorption rate. Therefore, the paper chooses the adsorption concentration of $60 \mathrm{mg} / \mathrm{L}$ for the adsorption of methyl orange, and the adsorption concentration of 20 $\mathrm{mg} / \mathrm{L}$ for the adsorption of Congo red.

\subsection{The effect of wastewater $\mathrm{pH}$ on the treatment effect}

It can be seen from Figure 5 that the adsorption rate of AFA on methyl orange and Congo red increases and then decreases. The adsorption rate of AFA on methyl orange at $\mathrm{pH} 4$ is the highest at $78 \%$, and the adsorption rate of AFA on Congo red at $\mathrm{pH} 3$ is the highest. It is $68 \%$, after which the adsorption rate is greatly reduced. This is because the adsorption performance of the dye is modified by sulfuric acid to open the closed pores, which is beneficial to expand the specific surface area, and the adsorption capacity can also be improved. When the $\mathrm{pH}$ is greater than 4 , the dye molecules will generate a large amount of negative charges due to ionization, and a large number of hydroxyl ions will be adsorbed on the surface of the fly ash, and the electrostatic repulsion between the dye and the fly ash will become weaker ${ }^{[9]}$. Therefore, the paper chooses AFA to adsorb methyl orange wastewater with a $\mathrm{pH}$ of 4 , and AFA to adsorb Congo red wastewater with a $\mathrm{pH}$ of 3 . 


\subsection{The influence of temperature on the treatment effect}

As shown in Figure 6, when the temperature of Congo red reaches $35^{\circ} \mathrm{C}$, the adsorption rate of AFA on Congo red is up to $82 \%$. When the studied temperature was adjusted to $45^{\circ} \mathrm{C}$, the maximum AFA adsorption rate for methyl orange was $75 \%$, after which the adsorption rate began to decrease rapidly. When the temperature is relatively low, the Brownian motion intensifies when the temperature rises, and accelerates the molecules in the wastewater to enter the pores of the AFA; when the temperature is too high, the adsorbed dye molecules will be desorbed due to the violent molecular thermal motion, so the adsorption rate will decrease after reaching the highest temperature at a certain temperature. Therefore, the paper chooses the adsorption temperature of AFA for methyl orange at $45^{\circ} \mathrm{C}$, and the adsorption temperature of AFA for Congo red at $35^{\circ} \mathrm{C}$.

\section{Conclusion}

(1) The simulated dyes of methyl orange and Congo red were treated by sulfuric acid, sodium hydroxide, high temperature modified AFA, SFA, TFA and unmodified FA respectively under the same conditions. It was found that the highest adsorption rate of SFA for methyl orange and Congo red was $51 \%$, the highest adsorption rate of TFA was $58 \%$, and the highest adsorption rate of AFA was $61 \%$ The treatment effect is good.

(2) This paper studied the adsorption performance of methyl orange and Congo red by AFA with different dosage, adsorption time, initial concentration, $\mathrm{pH}$ and temperature. The results showed that when the dosage of AFA was $1.00 \mathrm{~g}$, the adsorption time was $90 \mathrm{~min}$, the $\mathrm{pH}$ was adjusted to 4 , and the temperature was set at $45{ }^{\circ} \mathrm{C}$, the initial concentration of methyl orange wastewater was $60 \mathrm{mg} / \mathrm{L}$, and the highest adsorption rate was $75 \%$. When the dosage of AFA was $0.20 \mathrm{~g}$, the adsorption time was 60 min, the $\mathrm{pH}$ was adjusted to 3 , and the temperature was set to $35{ }^{\circ} \mathrm{C}$, the adsorption rate of Congo red with initial concentration of $20 \mathrm{mg} / \mathrm{L}$ was up to $82 \%$.

\section{References}

1. Jayaraman, S., Warrier, A.R. (2019) Dark catalytic degradation of industrial dye effluents using orthorhombic Tin monosulphide nanocatalyst. J. Mol. Liq., 301:112360.

2. Mu, B., Liu, L., Li W., Yang, Y. (2019) High sorption of reactive dyes onto cotton controlled by chemical potential gradient for reduction of dyeing effluents. J. Environ. Manage., 239(JUN.1):271-278.

3. Abolighasemabadi, M., Wael, B.M., Gil, A.C., Bisbe, H.R., Casabella, O., Soler,E.P.(2020) Azo-dye degradation by Mn-Al powders. J. Environ. Manage., 258:110012.

4. Bardestani, R., Roy, C., Kaliaguine, S. (2019) The effect of biochar mild air oxidation on the optimization of lead(II) adsorption from wastewater. J. Environ. Manage. , 240(JUN.15):404-420.

5. Dang, H., Chen, L., Chen, L., Yuan, M. Li, M. (2019) Hydrothermal synthesis of $1 \mathrm{~T}-\mathrm{WS}_{2}$ nanosheets with excellent adsorption performance for dye removal from wastewater. Mater. Lett., 254:42-45.

6. Bingnan, W., Yiqi, Y. (2019) Bio-adsorption technology $\%$ Cost assessment $\%$ Dye removal $\%$ Dye wastewater\%Industrial-scale wastewater treatment. Bioresour. Technol., 277:157-170.

7. Zhang, X., Li, Z., Lin, S. Theato, P., (2020) Fibrous Materials Based on Polymeric Salicyl Active Esters as Efficient Adsorbents for Selective Removal of Anionic Dye. ACS Appl. Mater. Interfaces, 12(18):21100-21113.

8. Gautam, R.K., Tiwari, I. (2020) Humic acid functionalized magnetic nanomaterials for remediation of dye wastewater under ultrasonication: Application in real water samples, recycling and reuse of nanosorbents. Chemosphere, 245(Apr.):125553.1125553.13.

9. Wang, J.W., Dai, L., Liu, Y.Q., Li, R.F., Xu, B. (2021) Adsorption Properties of $\beta$-cyclodextrin Modified Hydrogel for Methylene Blue. Carbohydr. Res., 501:108276. 